\title{
INTRODUCTION AND DEVELOPMENT OF A PRACTICAL LESSON FOR IMPROVING THE COMPETENCE OF MASTER STUDENTS IN PLANT BREEDING: THE USEFULNESS OF SPECIFIC SOFTWARE IN PHENOTYPING TASKS
}

\author{
C. Guijarro-Real, P. Gramazio, M. Plazas, A.M. Adalid-Martínez, A. Rodríguez- \\ Burruezo, J. Prohens, A. Fita \\ Instituto de Conservación y Mejora de la Agrodiversidad Valenciana (COMAV), Universitat \\ Politècnica de València (SPAIN)
}

\begin{abstract}
An essential step in many plant breeding programmes is the morphoagronomic phenotyping of the materials that are being developed, using standardized descriptors or, when not available, as it is the case of new crops, consensus guidelines to characterize them. Although many of the traits must be evaluated in the field, those related to the shape and size of leaves and fruits can be easily measured with specific software using digital pictures. This tool provides several advantages, including: 1) more accurate and objective measurements; 2 ) the possibility of measuring other traits of interest such as area or perimeter, that in other case would not be easily evaluated; or even 3 ) the possibility of delaying the analysis of pictures in order to focus on field traits. Therefore, the knowledge and management of this tool can become of high usefulness. The Plant Breeding Master offered by our institute is aimed at training professionals able to improve crops and develop new ones according to market trends, in addition to improve adaptation and resistance to biotic and abiotic stresses. Due to the importance of phenotyping considering any of the above breeding goals, in this paper we propose the introduction of a practical session in the mandatory subject "Instrumental Techniques": the management and comparison of adequacy of two specific software tools considering the material to be analyzed. As material, we propose a collection of pepper varieties for analysis of fruits, and a collection of rocket (Eruca and Diplotaxis spp.) germplasm for analysis of leaves, due to the broad variability observed in those materials. The MorphoLeaf v1.0 software will be used for the analysis of leaves, and the Tomato Analyzer 3.0 software will be used for the analysis of fruits and also for leaves. According to the design of the practical lesson, only one session of three hours is required, in which students will learn to properly digitalize materials considering the restrictions of each software and material used, and to obtain all the information needed in each case. In addition, there will be one hour of autonomous work in which both tools and the results obtained will be compared by the students, and a report will be prepared. This practical lesson allows students to acquire the competence for the correct use of different computer tools in the phenotyping task. The comparison of analyses using different scan adjustments and software will allow students to understand the disadvantages of each option and problems that could occur, in order to minimize them. In summary, this practical lesson gives a tool for improving the future phenotyping works of students during their careers, teaching them to consider the best software prior to analysis in order to improve the digitalizing step according to software restrictions, and to obtain more accurate information with a reduction of working time, thus increasing efficiency.
\end{abstract}

Keywords: Diversity, MorphoLeaf, morphology, Plant Science studies, specific competence, Tomato Analyzer.

\section{INTRODUCTION}

Master studies are addressed to improve the knowledge of post-graduate students, providing advanced training for a professional and research specialization [1]. In many studies related to Plant Sciences, professionals may need to evaluate the materials in terms of genetics, morphology and/or quality. Thus, Master studies should provide essential knowledge for developing these tasks successfully. In the particular case of Plant breeders, phenotyping the materials that are going to be used is essential in order to search for variability. In fact, one of the success points in a breeding programme is the presence of genetic variability among materials, in order to exploit it [2]. Moreover, phenotyping tasks are usually needed during all programme, and can be essential for describing the final variety if obtained. With this aim, standardized descriptors, used for 
characterizing vegetative and reproductive traits, are available for many economically important crops [e.g., 3, 4]. Even when standardized descriptors are not available, for instance in the case of new crops, the former are used as guidelines for the same purpose.

Although these descriptors are prepared to be manually characterized, some measurements such as size, shape and colour-related traits can be inaccurate. Moreover, collecting data is timeconsuming and, in many cases, characters are subjected to bias. As a way to reduce inaccuracy and increase efficiency, specific software tools have been developed, using digital pictures to facilitate phenotyping tasks. These softwares reduce wrong measurements, eliminate errors related to subjective scoring, and are helpful for determining other interesting traits that are not easy to quantify manually, such as total leaf area [5].

Our Plant Breeding Master has a special focus on developing new crops and varieties. For that, precise phenotyping tasks of the germplasm resources are of vital importance, and the use of advanced phenotyping techniques can become essential for obtaining the precision needed [6]. Thus, in order to increase the competence of students from our Plant Breeding Master, but also for other Plant Science masters, we devised of a software-assisted phenotyping practical lesson in the mandatory subject "Instrumental Techniques". The lesson is aimed at the management and comparison of the adequacy of two specific software tools considering the material to be analyzed. As material, we propose a collection of pepper (Capsicum spp.) varieties for analysis of fruits, and a collection of rocket (Eruca and Diplotaxis spp.) germplasm for the analysis of leaf morphology.

We hypothesize that the introduction of this practical lesson may contribute to an improved learning process, providing students with the knowledge of using software tools adapted to phenotyping and description tasks. Due to the importance of phenotyping in many breeding programmes, we consider of great relevance to introduce and compare different software depending on the specific goals and materials used. In summary, we consider that using these tools in a practical lesson will increase the competence of students in using technology as a support for improving phenotyping tasks, in terms of accuracy, efficiency, and analysis of higher number of traits.

\section{THE PRACTICAL SESSION}

The practical session requires three on-site hours plus one hour of autonomous work to be completed. It is therefore designed as one practical lesson of three hours, and autonomously completed within the next seven days. The lesson takes place in a computer room provided with 20 computers, as it is the maximum number of students in the subject "Instrumental Techniques" of the Plant Breeding Master offered by our Institute. Prior to the lesson, the MorphoLeaf v1.0 [7] and the Tomato Analyzer v3.0 software [8] will be installed. In addition, students will have free access to the computers during the next seven days, in a previously defined timetable, in order to finish the autonomous work.

The day of the practical lesson, the instructor provides a collection of leaves belonging to Eruca and Diplotaxis spp. genera (commonly known as rocket species), together with a collection of pepper fruits (Capsicum spp.), previously gathered and stored at $4^{\circ} \mathrm{C}$ in conditions of high humidity to avoid excessive transpiration. The materials used present a great variation in morphological traits, as previously described [5, 9], and are easy to work with, reasons why they were chosen for the practical lesson. The first step is to digitalize the materials that are being used, task that is performed in pairs with the assistance of the instructor. Since materials must be handled in a different way depending on the type (it is, leaves or fruits), and also considering that the different software have different digitalizing requirements, students are guided by a scheme provided at the beginning of the lesson, in order to successfully digitalize the images (Fig. 1). 


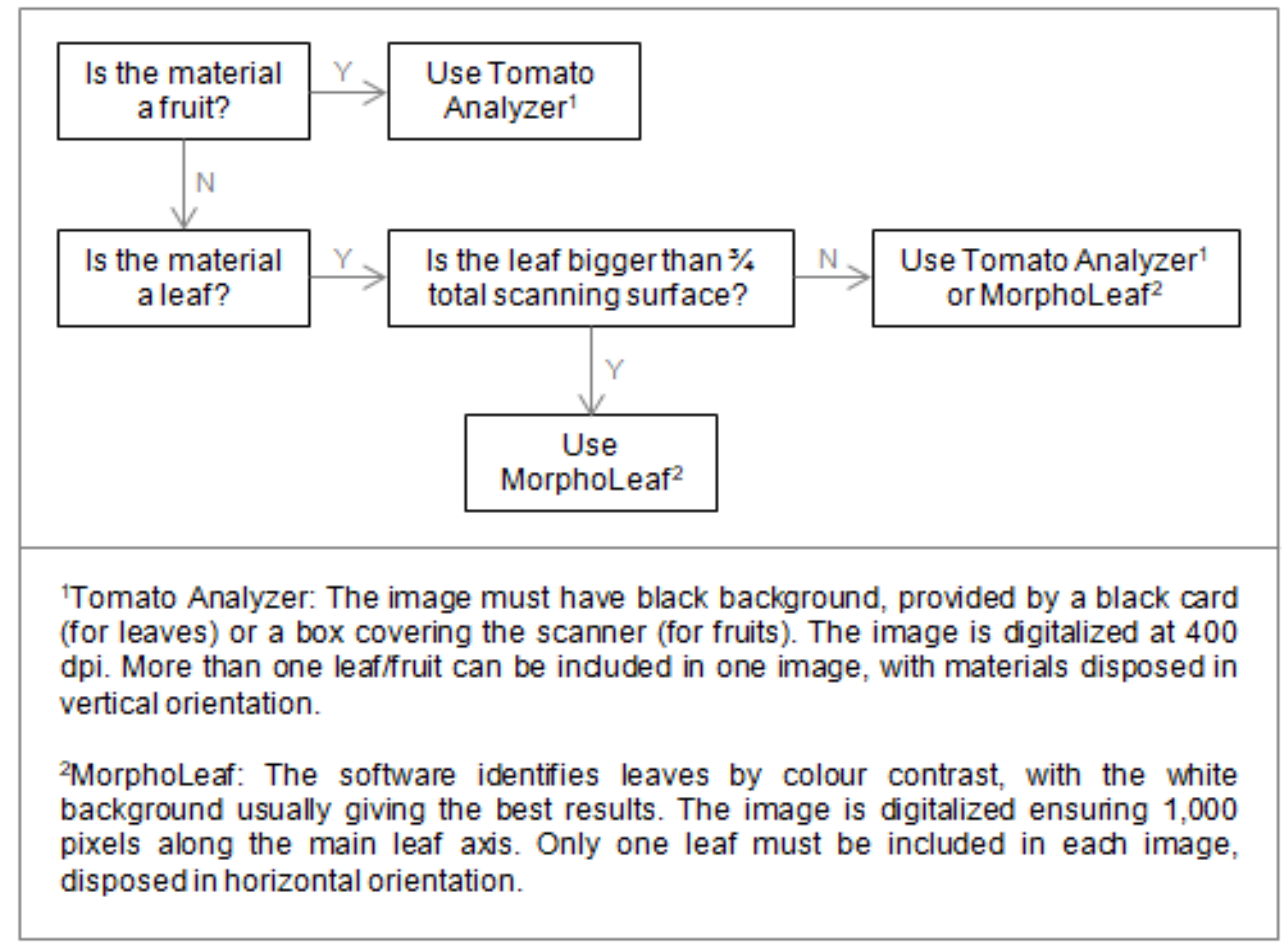

Figure 1. Schematic guide for determining the adequate requirements in the material digitalizing step.

In the second part of the practical lesson, the students learn how to process the images with different software tools. With this purpose, the instructor guides students during this learning process, and ask them to take concise notes on how to process images. The tasks involved in the learning process include, for both Tomato Analyzer and MorphoLeaf tools, the following steps:

1 To introduce the image in the program and to verify that the image and software information match. Students must learn in this step how to introduce properly the size information of the image in the software to ensure that the measurements obtained are real (Fig. 2).
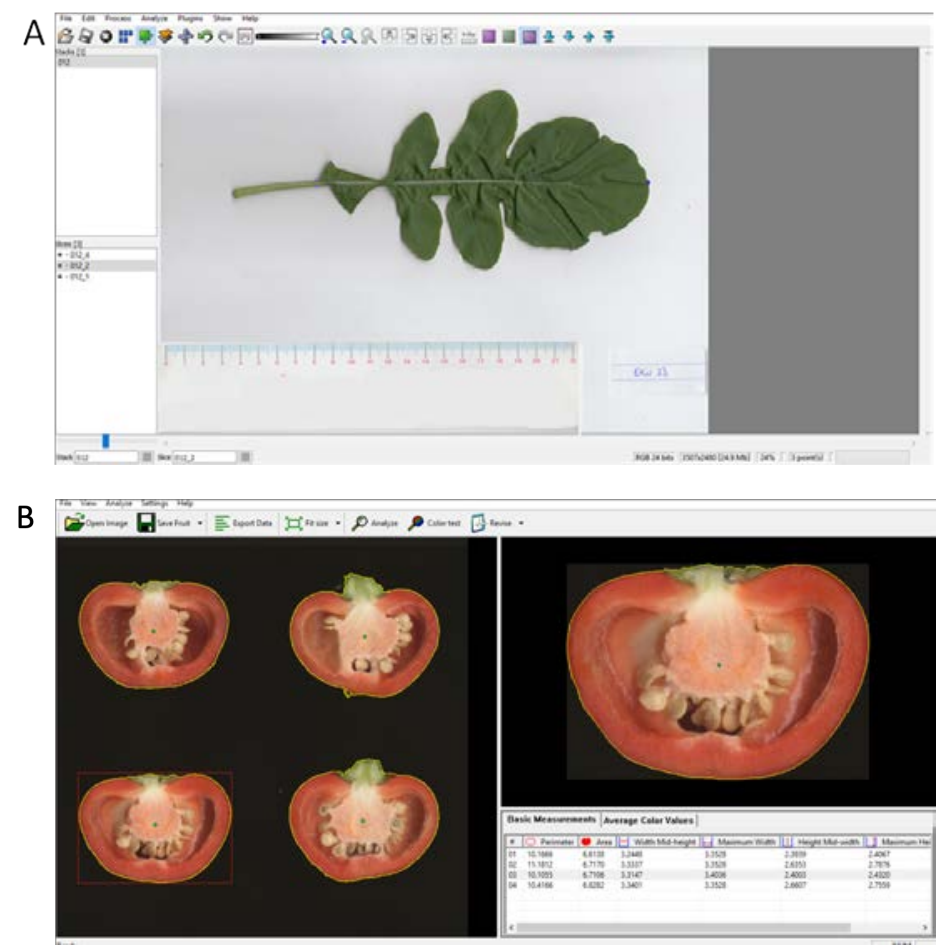

Figure 2. A) Example of scanned image of a leaf introduced in the MorphoLeaf tool for analysis.

B) Example of scanned image of fruits introduced in the Tomato Analyzer software for analysis. 
2 To draw properly the perimeter of the material being analyzed. In both software tools, the perimeter is automatically drawn by the software and must be checked by the user. In case the user detects errors, there is the possibility of correcting them by manual drawing (Fig. 3).
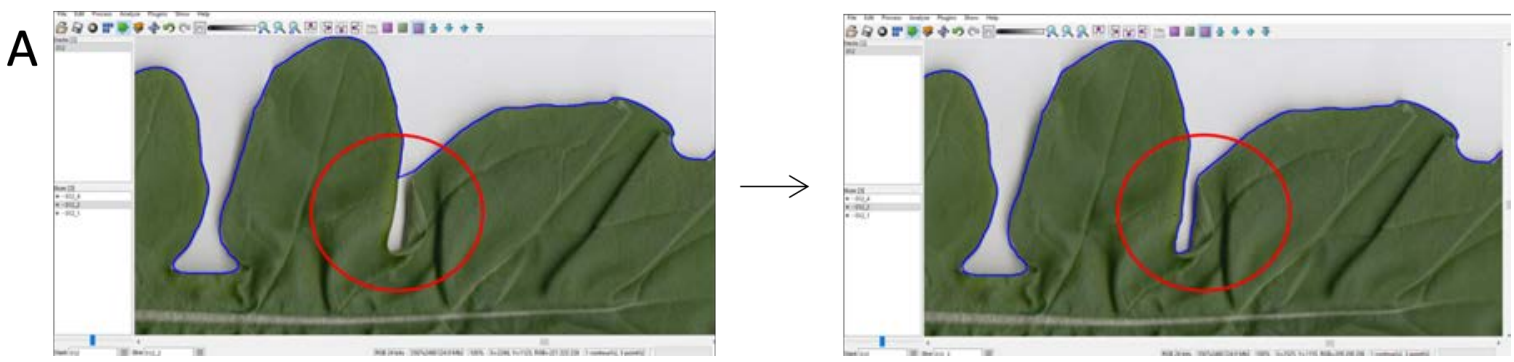

Figure 3. Example of manual correction in the perimeter using the MorphoLeaf tool.

3 To save the file and the measurements of interest.

At the end of the process, the students must be able to handle the software and process successfully an image. However, in some cases, there can be troubles that difficult the image processing. Those are mainly related to the identification of the leaf/fruit by the software, and are usually due to the size of the materials (it is, they are too big or small to be recognized as a leaf or fruit). Consequently, after ensuring that students can autonomously work with the software tools, the instructor takes an adequate time to explain those possible troubles and how to correct them, and asks students to take specific notes to solve future problems.

The last part of the practical lesson is dedicated to practice with the tools, and includes the remaining time of the lesson plus the additional one hour of autonomous work. Using all the images scanned at the beginning of the lesson, each student has to analyze an image of five fruits with the Tomato Analyzer tool, and five images of one leaf each using the MorphoLeaf software. The students will have seven days to complete this task.

In order to evaluate the knowledge acquired and the competence of successfully phenotyping assisted by computer, students are asked to fill a questionnaire (Table 1), providing also the files obtained in each case. In addition, some questions related to the perception that students have concerning the learning process in this practical lesson are included. Thus, the questionnaire is also used as a tool for making students reflect on the advantages and/or disadvantages of the computer assisted phenotyping, as well as a tool for continuously improving the lesson.

Table 1. Questionnaire to be filled up by students as evaluation of the practical lesson.

\begin{tabular}{|c|c|c|c|c|c|c|c|c|c|}
\hline \multicolumn{10}{|c|}{ Results obtained } \\
\hline \multicolumn{10}{|c|}{ 1. Leaf measurements (MorphoLeaf software) } \\
\hline $\begin{array}{l}\text { Leaf } \\
\text { code }\end{array}$ & \multicolumn{2}{|c|}{$\begin{array}{l}\text { Blade } \\
\text { length } \\
(\mathrm{cm})\end{array}$} & $\begin{array}{c}\text { Max } \\
\text { blade } \\
\text { width } \\
(\mathrm{cm}) \\
\end{array}$ & \multicolumn{2}{|c|}{$\begin{array}{l}\text { Petiole } \\
\text { width } \\
(\mathrm{mm})\end{array}$} & $\begin{array}{l}\text { Blade } \\
\text { perimeter } \\
\text { (cm) }\end{array}$ & $\begin{array}{l}\text { Blade area } \\
\qquad\left(\mathrm{cm}^{2}\right)\end{array}$ & \multirow[t]{2}{*}{$\begin{array}{l}\text { Upper } \\
\text { teeth } \\
\text { number }\end{array}$} & $\begin{array}{l}\text { Lower teeth } \\
\text { number }\end{array}$ \\
\hline & & & & & & & & & \\
\hline & & & & & & & & & \\
\hline & & & & & & & & & \\
\hline & & & & & & & & & \\
\hline \multicolumn{10}{|c|}{ 2. Fruit measurements (Tomato Analyzer software) } \\
\hline $\begin{array}{l}\text { Fruit } \\
\text { code }\end{array}$ & $\begin{array}{l}\text { Max } \\
\text { length } \\
(\mathrm{cm})\end{array}$ & $\begin{array}{l}\text { Max } \\
\text { width } \\
(\mathrm{cm})\end{array}$ & & & $\begin{array}{l}\text { Fruit } \\
\text { area } \\
\left(\mathrm{cm}^{2}\right)\end{array}$ & $\begin{array}{c}\text { Pericarp } \\
\text { area } \\
\left(\mathrm{cm}^{2}\right)\end{array}$ & $\begin{array}{l}\text { Ellipsoid } \\
\text { shape }\end{array}$ & $\begin{array}{l}\text { Circular } \\
\text { shape }\end{array}$ & Rectangular shape \\
\hline & & & & & & & & & \\
\hline & & & & & & & & & \\
\hline & & & & & & & & & \\
\hline & & & & & & & & & \\
\hline
\end{tabular}




\begin{tabular}{|l|c|c|c|c|c|}
\hline \multicolumn{7}{|c|}{ Personal questionnaire } & $\begin{array}{c}1 \\
\text { Totally } \\
\text { disagree }\end{array}$ & $\begin{array}{c}2 \\
\text { Disagree }\end{array}$ & $\begin{array}{c}3 \\
\text { Not sure }\end{array}$ & $\begin{array}{c}4 \\
\text { Agree }\end{array}$ & $\begin{array}{c}5 \\
\text { Totally } \\
\text { agree }\end{array}$ \\
\hline $\begin{array}{l}\text { The explanations of the teacher have been } \\
\text { clear enough to understand the lesson }\end{array}$ & & & & & \\
\hline $\begin{array}{l}\text { Tomato Analyzer seems a useful tool for } \\
\text { phenotyping tasks of fruits and/or leaves }\end{array}$ & & & & & \\
\hline $\begin{array}{l}\text { MorphoLeaf seems a useful tool for } \\
\text { phenotyping tasks of leaves }\end{array}$ & & & & & \\
\hline $\begin{array}{l}\text { Overall, I think that using these tools } \\
\text { increases the accuracy of phenotyping works }\end{array}$ & & & & & \\
\hline $\begin{array}{l}\text { Overall, I think that using these tools } \\
\text { increases the efficiency of phenotyping works } \\
\text { (from the gathering of material to analysis) }\end{array}$ & & & & & \\
\hline $\begin{array}{l}\text { I would consider the use of these tools in my } \\
\text { career for helping phenotyping tasks }\end{array}$ & & & & & \\
\hline $\begin{array}{l}\text { Comments (related to the lesson, materials, } \\
\text { tools...) }\end{array}$ & & & & \\
\hline
\end{tabular}

\section{CONCLUSIONS}

The tasks developed during the practical lesson proposed should provide students with the competence of developing phenotyping works with specific software assistance. Many phenotyping descriptors include traits related to the leaf as well as others related to the fruit. Thus, our aim is that after the practical lesson, students are able to address morphological analyses of these plant organs by means of specific software assistance. The evaluation proposed matches with the goal of the lesson, since students are asked to obtain properly the measurements asked. In addition, some key points are addressed in the lesson, including aspects related to the digitalizing step and software restrictions, and problems that can occur during the processing of images. Paying special attention to these points will help future breeders to take proper decisions prior to the analyses, thus minimizing the problems during the processing step and increasing the efficiency of the task. Finally, the second part of the questionnaire has the aim of making students think about the advantages of this type of assisted phenotyping, which can be very helpful during their careers.

\section{ACKNOWLEDGEMENTS}

Carla Guijarro-Real is grateful to the Ministerio de Educación, Cultura y Deporte of Spain for a predoctoral FPU grant (FPU14-06798). Pietro Gramazio is grateful to Universitat Politècnica de València for a post-doctoral contract (PAID-10-18) within the Programa de Ayudas de Investigación y Desarrollo initiative. Mariola Plazas is grateful to Generalitat Valenciana and Fondo Social Europeo for a post-doctoral grant (APOSTD/2018/014). Ana M Adalid-Martínez is grateful to the Ministerio de Ciencia, Innovación y Universidad of Spain for its support with a post-doctoral contract (PTA201511502-I) within the Subprograma Personal Técnico de Apoyo initiative.

\section{REFERENCES}

[1] A. Ismail, N. Abiddin, A. Hassan. "Improving the development of postgraduates' research and supervision", International Journal of Educational Studies vol. 4, pp. 78-89, 2011.

[2] K. Voss-Fels, R.J. Snowdon. "Understanding and utilizing crop genome diversity via highresolution genotyping", Plant Biotechnology Journal vol. 14, pp. 1086-1094, 2016.

[3] IPGRI. "Descriptors for Rocket (Eruca spp.)", Rome: International Plant Genetic Resources Institute, 1999. 
[4] IPGRI, AVRDC \& CATIE. "Descriptors for Capsicum (Capsicum spp.)", Rome: International Plant Genetic Resources Institute; Taipei: the Asian Vegetable Research and Development Center; Turrialba, the Centro Agronómico Tropical de Investigación y Enseñanza, Turrialba, 1995.

[5] P. Tripodi, B. Greco. "Large Scale Phenotyping Provides Insight into the Diversity of Vegetative and Reproductive Organs in a Wide Collection of Wild and Domesticated Peppers (Capsicum spp.)", Plants vol. 7, article 103, 2018. DOI: 10.3390/plants7040103

[6] L. Li, Q. Zhang, D. Huang. "A review of imaging techniques for plant phenotyping", Sensors vol. 14, pp. 20078-20111, 2014.

[7] E. Biot, M. Cortizo, J. Burguet, A. Kiss, M. Oughou, A. Maugarny-Calès, B. Gonçalves, B. Adroher, P. Andrey, A. Boudaoud, P. Laufs. "Multiscale quantification of morphodynamics: MorphoLeaf software for 2D shape analysis", Development vol. 143, pp. 3417-3428, 2016.

[8] M.T. Brewer, L. Lang, K. Fujimura, N. Dujmovic, E. Van der Knaap. "Development of a controlled vocabulary and software application to analyze fruit shape variation in tomato and other plant species". Plant Physiology vol. 141, pp. 15-25, 2006.

[9] F. Taranto, G. Francese, F. Di Dato, A. D'Alessandro, B. Greco, V. O. Sanajà, A. Pentangelo, G. Mennella, P. tripodi. "Leaf metabolic, genetic, and morphophysiological profiles of cultivated and wild rocket salad (Eruca and Diplotaxis spp.)", Journal of Agricultural and Food Chemistry vol. 64, pp. 5824-5836, 2016. 